\title{
Comprehending the Psychosocial Characteristics of Space through an Elective Course: The Experience of the Body and Cognitive Mapping in Design Education
}

\author{
Nevset Gul Canakcioglu () \\ Ozyegin University, Faculty of Architecture and Design, Istanbul, Turkey
}

Received: October 5th 2020, Revised: November 8th 2020, Accepted: November 9th 2020

Refer: Canakcioglu, N. G., (2020), Comprehending the Psychosocial Characteristics of Space through an Elective Course: The Experience of the Body and Cognitive Mapping in Design Education, Journal of Design Studio, V.2, N.2, pp 41-55,

ORCID: 0000-0002-8289-3601

DOI: $10.46474 /$ jds.805377 https://doi.org/10.46474/jds.805377

\begin{abstract}
Architectural studio courses are structured for students to comprehend an existing urban fabric with its physical and social components for the purpose of solving a specific design. In this context, as students develop their conceptual ideas, they are also expected to assume probable interactions that are supposed to occur between users and space. However, students often face with difficulties in embracing the space with its psychological, social and sensual dimensions and occasionally ignore these unseen parameters of space such as spatial perception, user needs, privacy, user satisfaction, and etc. In this regard, elective courses become essential in supporting the student's interdisciplinary comprehension of space. An elective course titled Spatial Perception and Cognition is structured with this intention to support the student's interdisciplinary understanding of space both in theoretical and kinesthetic means. Thus, in the context of the course, the concept of space is not only introduced through theoretical seminars, but also through an experiential participation of the students themselves where they can actively perform daily activities by the guidance of a blind guide, in Dialog in the Dark which is a thematic dark environment where students experience various urban nodes through scent, sound, wind and texture. Upon completion of the experience, students are invited to a cognitive mapping session through which they reflected their spatial experiences grasped via their senses. In conclusion, cognitive maps show that when eyesight is eliminated, other senses also play a very important role in comprehending the sensual and psychological characteristics of space.
\end{abstract}

Keywords: Architecture Studio, Cognition, Cognitive Mapping, Design Education, Spatial Perception.

\section{Introduction}

The students in architecture departments, in every upcoming semester, are expected to cope with the problems arising from the multifaceted parameters of urban life and think of these parameters through a multidisciplinary perspective. During the stage of design, the designer candidates go through such a process that while they attempt to define the spatial relations between the spaces hierarchically, they also try to determine and anticipate the user groups, the frequency of their use of the spaces, public, semi-public, private shift between indoor and outdoor spaces according to the theme of the project. 
At every stage of the design process, the student as a designer candidate is expected to be aware of the emerging structure of the upcoming artefact regarding how the inseparable unity of the spatial component is perceived by its users, what sort of dialogues tend to be established between diverse user groups, what kind of changes the spatial organization will cause in the emotional states of the users. Within this context, elective courses which students select to make themselves more specialized in specific subjects, can provide cognitive support in understanding the interaction between space and user.

The elective course titled Spatial Perception and Cognition which is structured with such an aim, aspires to support students embrace the space not only with its topological and geometrical characteristics but also with its psychosocial characteristics. As a result of the case study conducted in this research, based on the bodily experiences of the students taking the course in a totally dark thematic environment and a cognitive mapping session afterwards, it was found that students define the concept of space not only through the physical parameters such as dimension, area, scale and etc. but also through its psychosocial characteristics such as its tactile, auditory, olfactory and even gustative characteristics.

\section{The Aim and Process of the Course Spatial Perception and Cognition}

The aim of the Spatial Perception and Cognition course is to convey an interdisciplinary thinking in architecture focusing on the reciprocal interaction between the individual and space within the scope of environment and behaviour theories through the concepts of perception and cognition. In this context, in the scope of this course, besides conveying the theoretical studies in spatial perception and cognition (Hall, 1966; Hart and Moore, 1973; Canter, 1977; Moore, 1979; Moore, 1985; Piaget and Inhelder; 1967; Rapoport; 1969) the concept of space is also embraced with its sensual attributes that have an effect on user experience such as visual, auditory, kinaesthetic, tactile and olfactory attributes (Lynch, 1960; Lawson,
2001; Merleau-Ponty, 1961; Merleau-Ponty, 1982; Pallasmaa, 2005). Additionally, the concept of spatial cognition which relates to how the individual learns, comprehends and constructs the space through distinctive cognitive maps is also covered through the researches of scholars beginning from the time that the theory of environmental psychology was first introduced (Tolman, 1948; Kaplan, 1973; Downs and Stea; 1973; Piaget and Inhelder; 1967).

Through these aims, by completing this course, it is aimed the students to gain the following learning outcomes:

- Comprehend the parameters affecting the behaviour of the individual within various physical environments.

- Internalize the existence of a reciprocal relationship between space and individual as a user.

- Comprehend the concept of space as a multidimensional component of the physical environment including social, cultural, physiological and psychological constituents.

- Internalize the concept of space as a perceptual product generated by ongoing cognitive processes of the individual through the construction of knowledge resulting from the spatial experiences of the individual.

The course is regularly carried out for 14 weeks during a semester, once a week, for two hours. In the first lecture of the course, the course is introduced to arouse curiosity about the multidimensional meanings of the concepts of spatial perception and cognition. Therefore, in order to give hints about the reciprocal relationship between the space and the user, various visuals that represent different kinds of spaces, including urban, rural, centuries-old, built in the late modern era, private, public, semi-public and etc. are shown so that the students can grasp an initial idea of the concept of spatial perception and actually understand that this course may also have an aspect affecting and developing their cognitive processes in design for the benefit of their design studio courses. 
In the next four weeks, a series of theoretical seminars are held for the purpose of increasing the students' level of knowledge on environment and behaviour theories. In this context, it is worthwhile to remember the important quotation of Winston Churchill which read as follows, "We shape our buildings; thereafter they shape us", which specifically emphasizes that every space we live and work in our daily lives has various impacts on us, while these spaces also affect us. The theoretical part of the inseparable relationship between space and the user is conveyed through consecutive seminars every week.

Discussions on the theoretical background of environment and behaviour theories start based on the arguments of Moore $(1979,18)$ emphasizing that, "architecture is the art, which above all others, combines expression, technology, and the satisfaction of human needs. Its purpose is to make places where people feel more human, more alive, more fulfilled" while trying to describe what decent architectural artefact actually is. During these discussions, students take a deeper look into and try to find an answer(s) to the question of "how often do we really pay serious attention to the needs of the user, to the behavioural, social and cultural determinants of the design, and to the role of the good design in affecting human behaviour?" which was put forward by Moore (1979, p.18) through students' active participation and group discussions.

Soon after two weeks, the students are asked to select specific articles and make presentations in groups on the key concepts of the course for the purpose of making active participants in the following weeks. The key concept of environmental perception is embraced based on Gestaltian (Smith, 1988; Rock and Palmer, 1990), transactional (Ittelson, 1976), ecological (Gibson, 1966) and cultural approaches (Rapoport, 1969) while the other key concepts such as environmental cognition (Piaget and Inhelder, 1967), behaviour setting (Barker, 1968), personal space (Sommer, 1959), privacy, territorial space (Hall, 1966) and environmental stress (Lawton and Nahemow, 1973) are embraced through theoretical backgrounds put forward by the scholars as well as through concrete examples in the history of architecture. While the topic of visual perception is embraced through the theory put forward by Kevin Lynch in his book -The Image of the City- in 1960, and other sensual characteristics of space are embraced through significant examples in the architectural history.

\subsection{Theoretical Background: The Dominancy of the Eye in Perception}

Merleau-Ponty (2004, p.50) opposes the precise distinction that classical science keeps a distance between space and the physical world. Space, according to Ponty, has a dimensionality through which it affects the beings involved in space, and is also affected by the beings themselves. Instead of a world where the distinction between identity and change is clearly defined, he asserts that we have a world where the "form and the content are mixed" and the boundary between them is blurred. In parallel with this phenomenological way of thinking about space, Bachelard (1994) states that in order to gain a holistic understanding of the concept of space, it is necessary to comprehend that there is a dialectical relationship between the empirical world of space and the way of thinking about space.

However, according to Lawson (2001), the sensory organ that is at the forefront in spatial perception is the eye since the perception of a person with a complete physical competence is heavily dependent on the sense of vision (Lawson, 2001) due to the instant delivery of a large environmental information even in the blink of an eye (Ungar, 2000). In parallel to this approach, according to Pallasmaa (2005), the eye has become the centre of both architectural and spatial perception and accordingly the representation of space due to the fact that the eye, compared to the other sensual modalities, collects the largest amount of perceptual data generated by the environment. This dominating effect of visual perception both in individual perception and in the field of design, the auditory, olfactory and tactile characteristics of space that also have strong impacts on human 
psychology to be sometimes ignored even by designers. In addition to that, as Ünlü mentions (1998), sensory perception through vision cannot only be a purely visual matter of fact but actually is related to how the individuals perceive their environment through their kinaesthetic experiences such as body movements which also include postures, gestures and actions.

Therefore, for a holistic perceptual process, it is necessary to perceive through all sensory organs, regardless of whether the perceived thing is an object or a spatial component. In parallel with this view, according to Ittelson (1951), action and perception are inextricably related to each other, because changes in one's perception processes cause changes in one's actions, and changes in one's actions cause new changes in perception processes. Gibson (1979), supporting this view, states that the process of comprehensively understanding space is an extension of perception, because the essence of knowledge about space is obtained as a result of perceptual process which results as an abstract concept in the mind.

Therefore, the holistic understanding and representation of space can also be expressed as the replication obtained through the recall of the perceptual inputs collected in the mind as a result of the individual's kinaesthetic experience and sensual perception (Downs and Stea, 1973; Jacobson, 1998). One of the studies that demonstrated the importance of the visually impaired individuals' kinaesthetic experiences in spatial perception (Passini and Proulx, 1988), showed that congenitally blind participants were able to represent the route they followed at a level very close to the sighted individuals who were the control group in the study. Another cognitive mapping research with the blind (Jacobson, 1998, p.303) showed that these visually impaired people achieve direct or indirect spatial and geographic awareness through their "language, audition, haptics, smell and taste" skills, as well as through understanding the "flow and motion" in space.
Consequently, as it is stated within the scope of the objectives of the course and this paper, it is hypothesized that the holistic perception of any space with all senses and the comprehension of this issue by the students is assumed to be very vital and essential in addressing the design problems that the students are working on in their design studios. For this reason, it is one of the primary objectives of this course that students experience this involvement through their own bodies and perceive the place thoroughly through all of their senses that they usually forget or ignore in their daily lives.

\section{Methodology}

In order to fully test the hypothesis of the study, an out-of-school visit to a thematic experiential setting called as Dialogue in the Dark has become an important content of the course for the purpose of making students become more aware of the dominant state of the sense of vision, as well as making them realize the importance of other sense organs for a holistic spatial perception.

\subsection{Case Study Environment}

Dialogue in the Dark, as it is mentioned on its web site (Url-1), is defined as "an exciting journey of exploring daily environments \& routines through the senses of touch, taste, smell and sound. With the help of white cane and guide you get a chance to explore the unseen, and learn to see in darkness. As you travel through Dialogue in the Dark exhibition, an invisible landscape emerges, composed out of sounds, scents, wind and textures. In tours that can last up to 1.5 hours you explore a park, a city, embark on a boat ride and enjoy coffee \& appetizers in a café. The experience allows you to have great fun and to discover how to find orientation and move in the dark, how to identify the world through the remaining senses, how to interact and communicate by relying on other senses, how to generate trust and cope with the unknown." Dialogue in the Dark, which is experienced in more than 30 countries and 130 cities with visitors over 8 million, has been serving at Gayrettepe Metro Station in Istanbul since 2013 (Url-2). In the thematic environment that hosts visitors in a 
total area of 1600 square meters, the visitors experience the daily life of Istanbul in a completely dark place in groups with the help of a blind guide.

After the participants are given white canes at the entrance, they follow a narrow and labyrinthine corridor and gradually step into a totally darkened environment (Figure 1), where they meet their blind guides in the total darkness. Visitors, who continue their routes under the guidance of their guides, experience a total of 12 different nodes including the entrance and exit areas. The experiential nodes can be summarized as follows (Figure 2):
- Entrance

- Meeting point with the guide

- Park

- Bicycle

- Market

- Car

- Crossing the street

- Tram

- Boat

- Braille Alphabet

- Café

- Exit

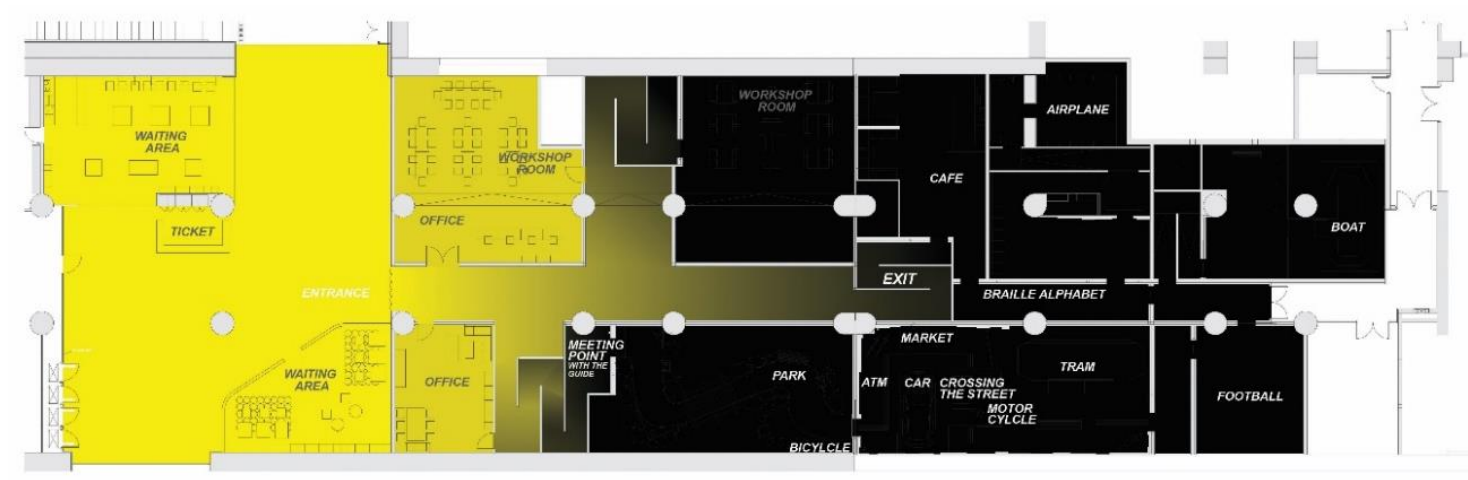

Figure 1: Transition from Bright Areas to Darkness in Dialog in the Dark Source: Sarlberberoglu et al., 2017

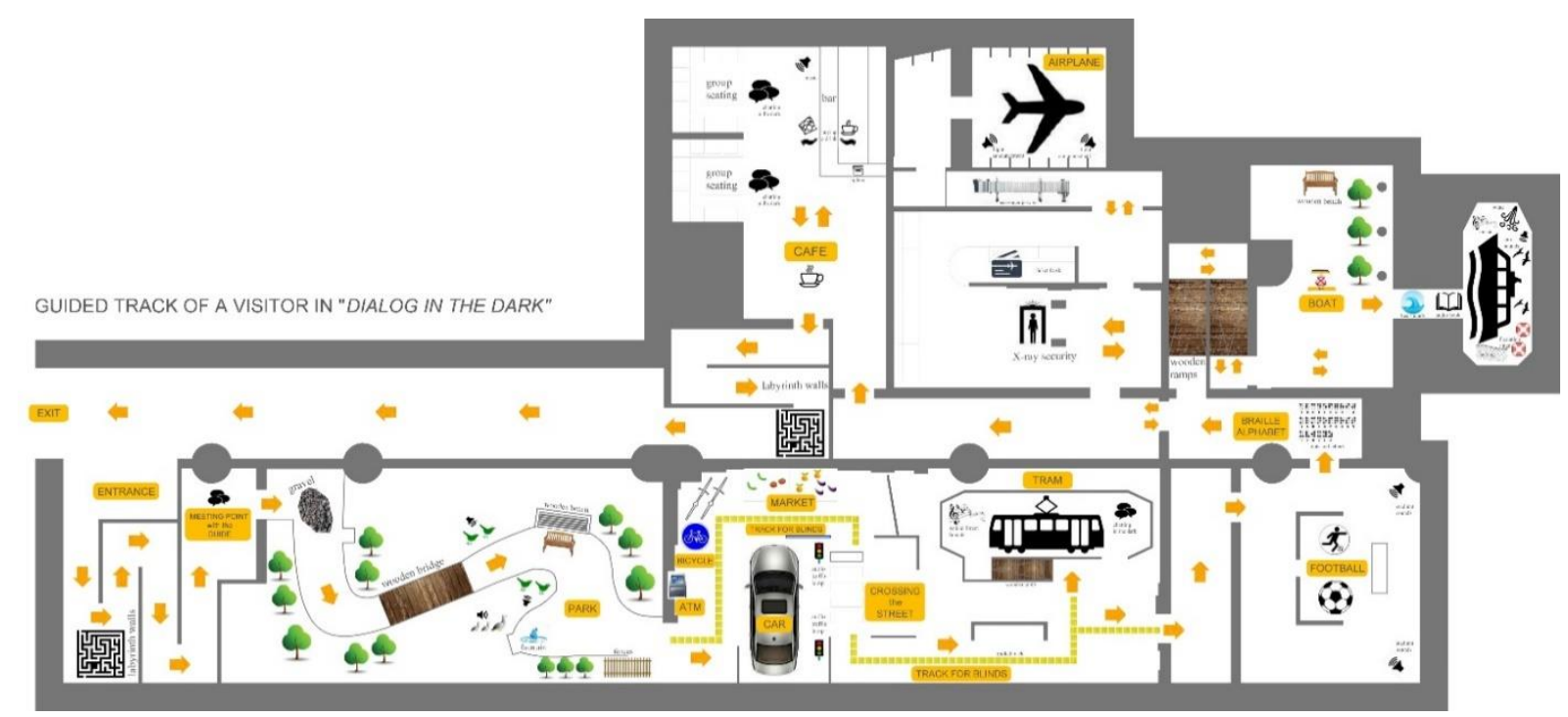

Figure 2: An Infographic Showing the Experiential Nodes in The Thematic Environment Source: Sartberberoglu et al., 2017 
In the setting, where each different node is equipped with various stimuli that arouse auditory, olfactory, tactile and gustative senses, the visitors respectively experience a park and a market of Istanbul, cross a road that is specially designed for the blind, take the well-known tram on Istiklal Street, cross the Bosporus with the ferry and finally, by ordering a drink or food in a cafe, they socialize with friends in the group. Participants who experience the daily life of Istanbul during the 90-minute experience, like the blind people who live the city's outdoors, experience the difficulties they have never experienced before, such as walking and getting off the sidewalk, getting on the tram, finding a place for themselves with the help of a white cane, they also notice the stimuli that they do not normally pay attention to in their daily lives, such as the music coming from the Flower Passage in Istiklal Street, a wide variety of sounds of the city, the horns, the traffic light with sound signal, or dangers including burns and injuries caused by a cup of hot tea.

In such a nonvisual thematic environment the aim is to enable students to discover various spatial components and other senses without relying on and using their visual abilities that they normally use in their daily lives, while also being aware of the potential of these senses in spatial perception.

\subsection{The Methodology of Cognitive Mapping Applied and its Outputs}

The participants of the study are selected from the group of students who have been taking the
Spatial Perception and Cognition course and voluntarily would like to experience the thematic environment of Dialogue in the Dark right after the students' experience in the setting for about 90 minutes, the students are invited to a cognitive mapping session through which they are asked to draw their route in the setting. In summary, this study is conducted by the analysis of a total of 76 cognitive maps represented by students, of which 29 were male and 47 were female.

Before starting the cognitive mapping session, it is announced to the students that they are free to draw and use any kind of text and graphical notes while representing their experience onto an A4 size of paper (Figure 3 and 4). The reason why they are asked to add text and graphical notes onto their cognitive maps is not only to reveal the experiential nodes they remember, but also to uncover the sensual data they have constructed in their cognition while they are experiencing these nodes (Figure 5 and 6). At the beginning of the cognitive mapping session, which lasts 20 minutes in total, in the first place, each of the students is given a pencil and they are allowed to work only with this pencil for about 10 minutes, after which the pencils are taken away from them and then each of the students is given a red pencil and allowed to work for another 10 minutes. The reason for carrying out the study in this way is to understand and differentiate which experiential nodes and what kind of sensual data -auditory, olfactory, tactile or gustative- the students remember in the first and second 10 minutes' sessions of the cognitive mapping process.
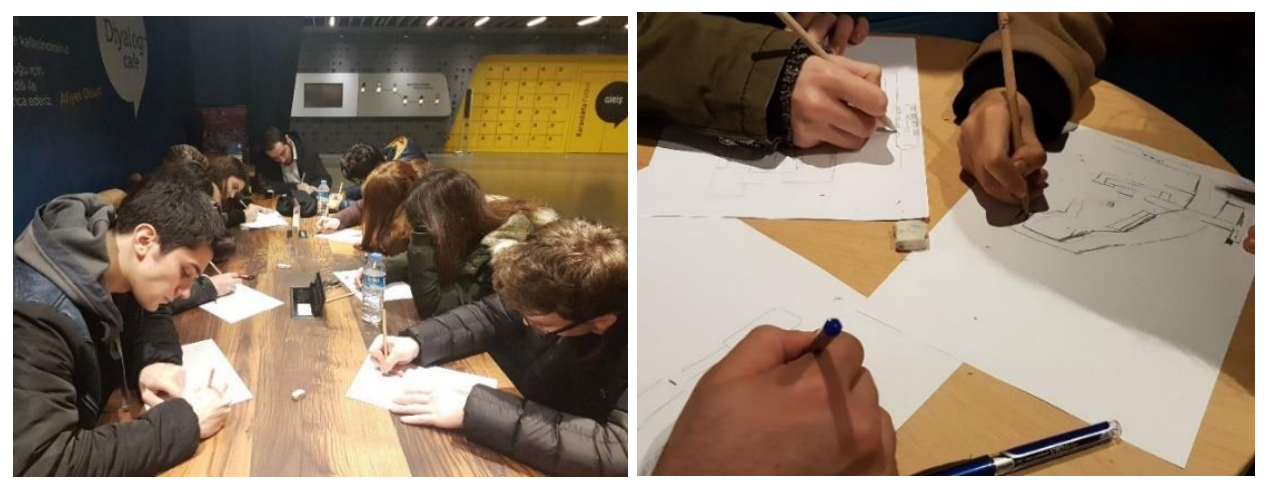

Figure 3-4. Students drawing during the cognitive mapping session right after the Dialog in the Dark experience.

Journal of Design Studio, v:2 n:2

Canakcioglu, N. G., (2020), Comprehending the Psychosocial Characteristics of Space through an Elective Course:

The Experience of the Body and Cognitive Mapping in Design Education 


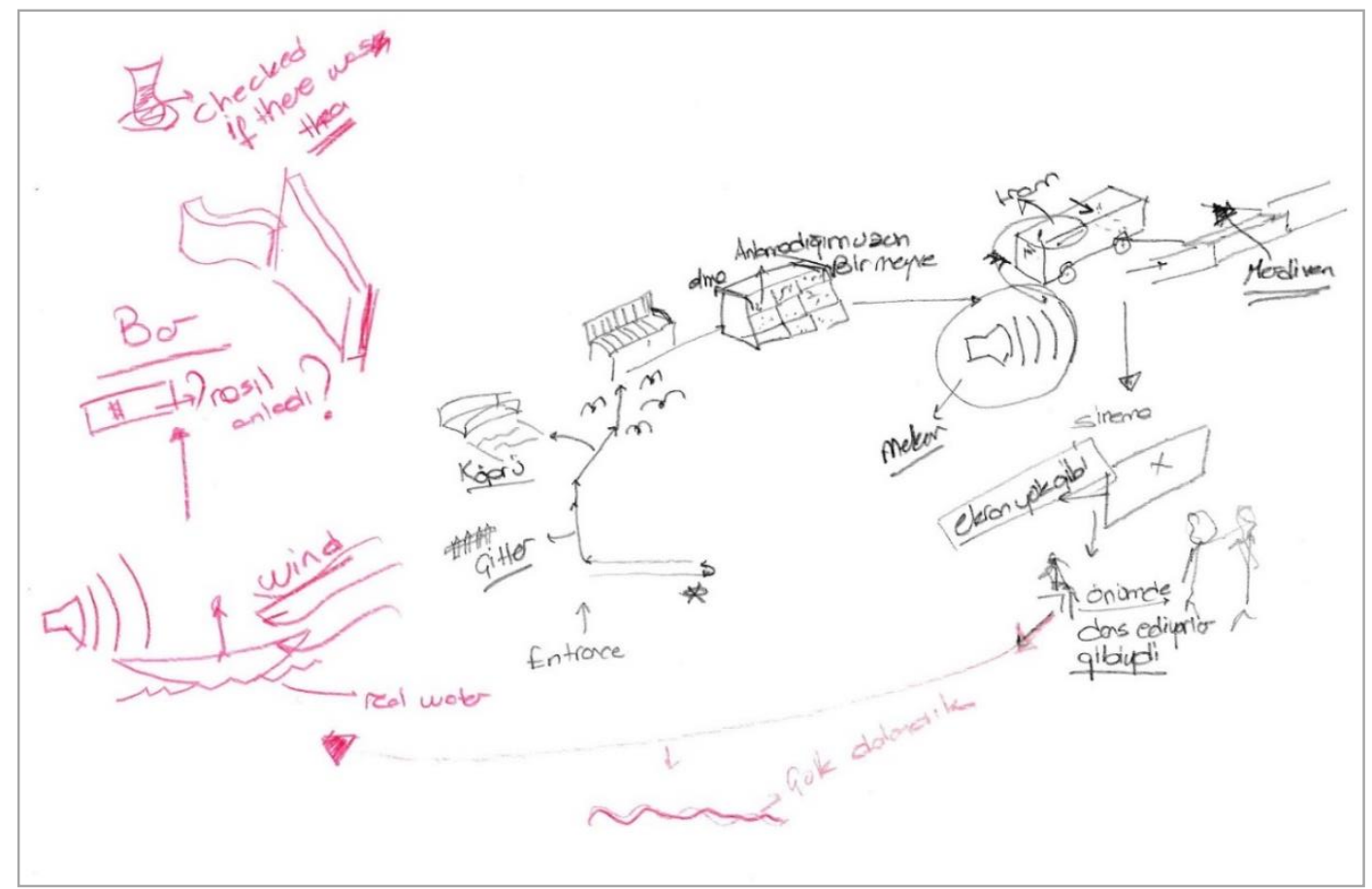

Figure 5. An example of a cognitive map (Male).

Source: Image Courtesy of the elective course titled Spatial Perception and Cognition

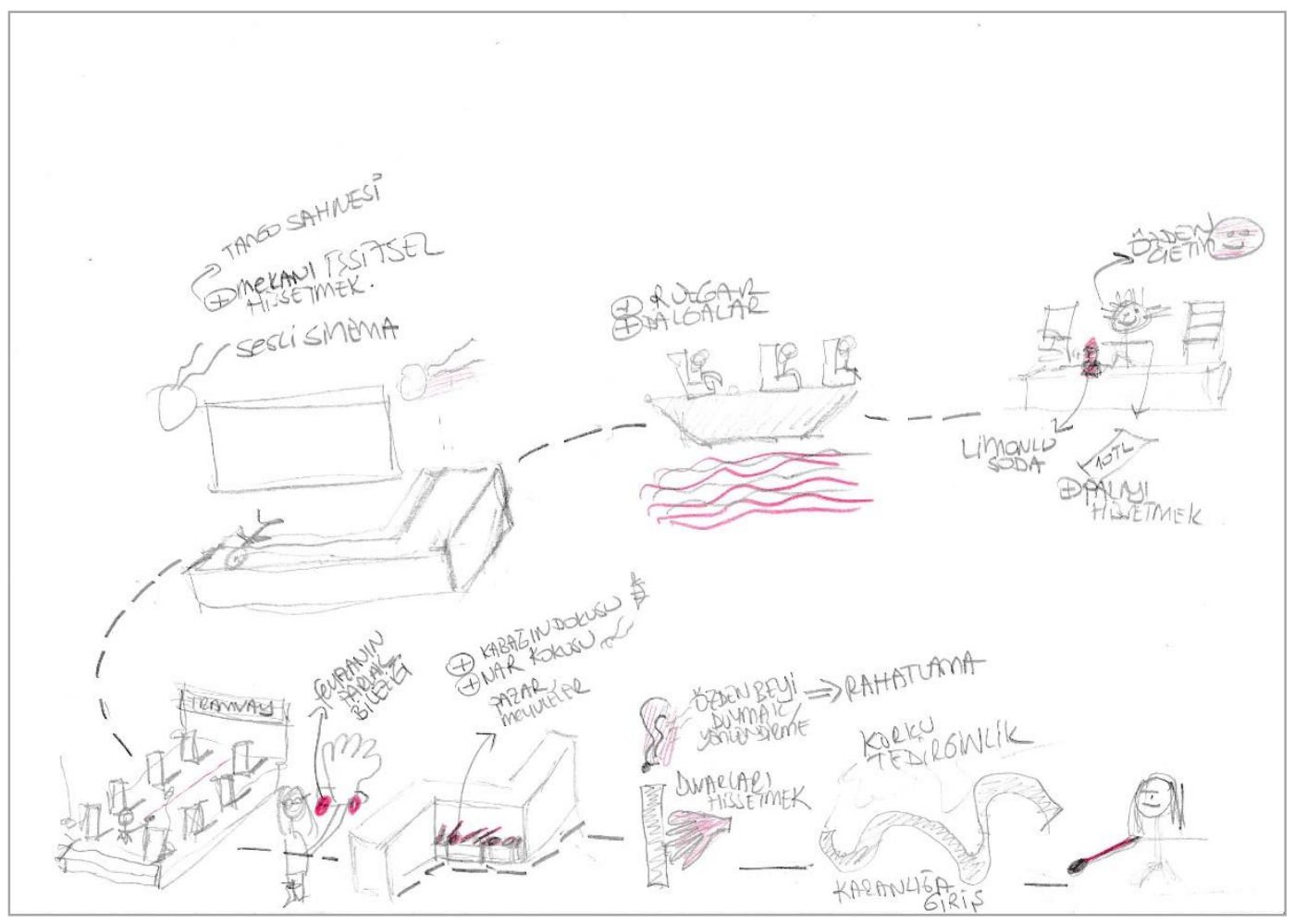

Figure 6. An example of a cognitive map (Female).

Source: Image Courtesy of the elective course titled Spatial Perception and Cognition 
Besides, the procedure in the analysis phase of the study is carried out as follows (Table 1);

- In the first place, the experiential nodes shown up on each cognitive map are counted one by one, and accordingly the total frequency of each experiential node represented on the maps is obtained. This information constitutes the dataset -one of the dependent variablesthat reveals which nodes are more recalled and represented on cognitive maps based on the participant's experience.

- Next, if any olfactory, auditory, tactile, or gustative sensual data is added regarding each experiential node, this data is also counted independently so that the total sensual frequency of every experiential node is revealed. This information constitutes the dataset -the other dependent variable- that reveals the sensual data frequency of each node in cases where there is no visual perception.

- Besides, the sensual datasets are also recorded whether they were drawn with a pencil or a red pencil to understand in which session the drawing was completed, in the first ten minutes' session or the second ten minutes' session. This information constitutes the dataset that reveals whether the sensual data is recalled and represented in the 1st or 2 nd drawing stage.

It should be mentioned that this methodology had also yielded fruitful results in the research of Sariberberoglu et al. (2017), through which they made the research with 25 architects to understand which sensual characteristic is more dominant in spatial perception in such a nonvisual environment. In parallel to the methodology and analysis phase of this study, the results of Sariberberoglu et al. (2017) also showed that the participants rely heavily on their tactile senses in such a place where they do not use the sense of sight and the syntactic characteristic of the spatial organization is not correlated with the frequency of cognitive representation of the individuals.

Table 1. Datasets accumulated through cognitive maps.

\begin{tabular}{|c|c|c|c|c|c|c|c|c|c|c|c|c|c|}
\hline \multirow{3}{*}{$\begin{array}{l}\text { Experiential } \\
\text { shown up }\end{array}$} & \multirow{3}{*}{ nodes } & \multicolumn{12}{|c|}{ Sensual data } \\
\hline & & \multirow{2}{*}{$\begin{array}{l}\text { Olfac- } \\
\text { tory }\end{array}$} & \multicolumn{2}{|c|}{ Draw order } & \multirow{2}{*}{$\begin{array}{l}\text { Audi- } \\
\text { tory }\end{array}$} & \multicolumn{2}{|c|}{ Draw order } & \multirow{2}{*}{ Tac-tile } & \multicolumn{2}{|c|}{ Draw order } & \multirow{2}{*}{$\begin{array}{l}\text { Gust } \\
\text { a-tive }\end{array}$} & \multicolumn{2}{|c|}{ Draw order } \\
\hline & & & $1^{s t}$ & $2^{\text {nd }}$ & & $1^{s t}$ & $2^{\text {nd }}$ & & $1^{s t}$ & $2^{\text {nd }}$ & & $1^{s t}$ & $2^{\text {nd }}$ \\
\hline Entrance & 69 & 0 & 0 & 0 & 0 & 0 & 0 & 54 & 51 & 3 & 0 & 0 & 0 \\
\hline $\begin{array}{l}\text { Meeting point } \\
\text { with the guide }\end{array}$ & 4 & 0 & 0 & 0 & 3 & 1 & 2 & 0 & 0 & 0 & 0 & 0 & 0 \\
\hline Park & 54 & 2 & 1 & 1 & 29 & 18 & 11 & 172 & 135 & 37 & 0 & 0 & 0 \\
\hline Bicycle & 7 & 0 & 0 & 0 & 0 & 0 & 0 & 1 & 0 & 1 & 0 & 0 & 0 \\
\hline Market & 41 & 20 & 16 & 4 & 1 & 0 & 1 & 19 & 15 & 4 & 0 & 0 & 0 \\
\hline Car & 0 & 0 & 0 & 0 & 0 & 0 & 0 & 0 & 0 & 0 & 0 & 0 & 0 \\
\hline $\begin{array}{l}\text { Crossing the } \\
\text { street }\end{array}$ & 28 & 0 & 0 & 0 & 25 & 16 & 9 & 23 & 18 & 5 & 0 & 0 & 0 \\
\hline Tram & 68 & 0 & 0 & 0 & 40 & 24 & 16 & 38 & 29 & 9 & 0 & 0 & 0 \\
\hline Boat & 61 & 0 & 0 & 0 & 44 & 20 & 24 & 91 & 50 & 41 & 0 & 0 & 0 \\
\hline $\begin{array}{l}\text { Braille } \\
\text { alphabet }\end{array}$ & 1 & 0 & 0 & 0 & 1 & 0 & 1 & 0 & 0 & 0 & 0 & 0 & 0 \\
\hline Café & 74 & 5 & 2 & 3 & 11 & 3 & 8 & 67 & 17 & 50 & 25 & 5 & 20 \\
\hline Exit & 45 & 1 & 1 & 0 & 1 & 1 & 0 & 21 & 6 & 15 & 3 & 0 & 3 \\
\hline $\begin{array}{l}\text { Total frequ- } \\
\text { ency }\end{array}$ & 452 & 28 & 20 & 8 & 155 & 83 & 72 & 486 & 321 & 165 & 28 & 5 & 23 \\
\hline
\end{tabular}

Journal of Design Studio, v:2 n:2

Canakcioglu, N. G., (2020), Comprehending the Psychosocial Characteristics of Space through an Elective Course: 


\section{Analyses and Results}

The analysis phase and the results of the study are presented in two parts. In the first part, numerical distributions of the datasets are shown and comparative bar graphs are presented (Figures 7,8 and 9). In the second part, simple regression test results conducted via SPSS (2018) between the two dependent variables are revealed. The two variables in simple regression correlations as described in the methodology section are as follows: (1) total frequency of each experiential node represented on cognitive maps, and (2) total sensual frequency of each experiential node represented on cognitive maps. Depending on the significance levels of the statistical data obtained, the hypothesis of the study is discussed in conclusion section.

In the first part of the analysis procedure, frequencies related to how many times each experiential node are drawn are calculated. When the total frequencies of the experiential nodes in the cognitive maps (Figure 7) are considered, it is found that the node that appeared with the highest amount of 74 is the café. In other words, after the students completed their experience in Dialog in the Dark, they have remembered and represented the node of café at the highest amount. The node of café is the last visited node of the thematic environment where food and drinks are ordered in the darkness, where money exchange is experienced and also a slight tension against the danger of burning is experienced when a hot drink is bought from the bar. At the same time, this node is the first place for the participants to have a seat for the first time after a 90-minutes of stressful experience where they socialize and chat with the group and the guide as if they are in a real café environment. Briefly, the reason why the node of café appeared at the highest amount could be that the participants had many sensual experiences in this setting that make them recall this node.

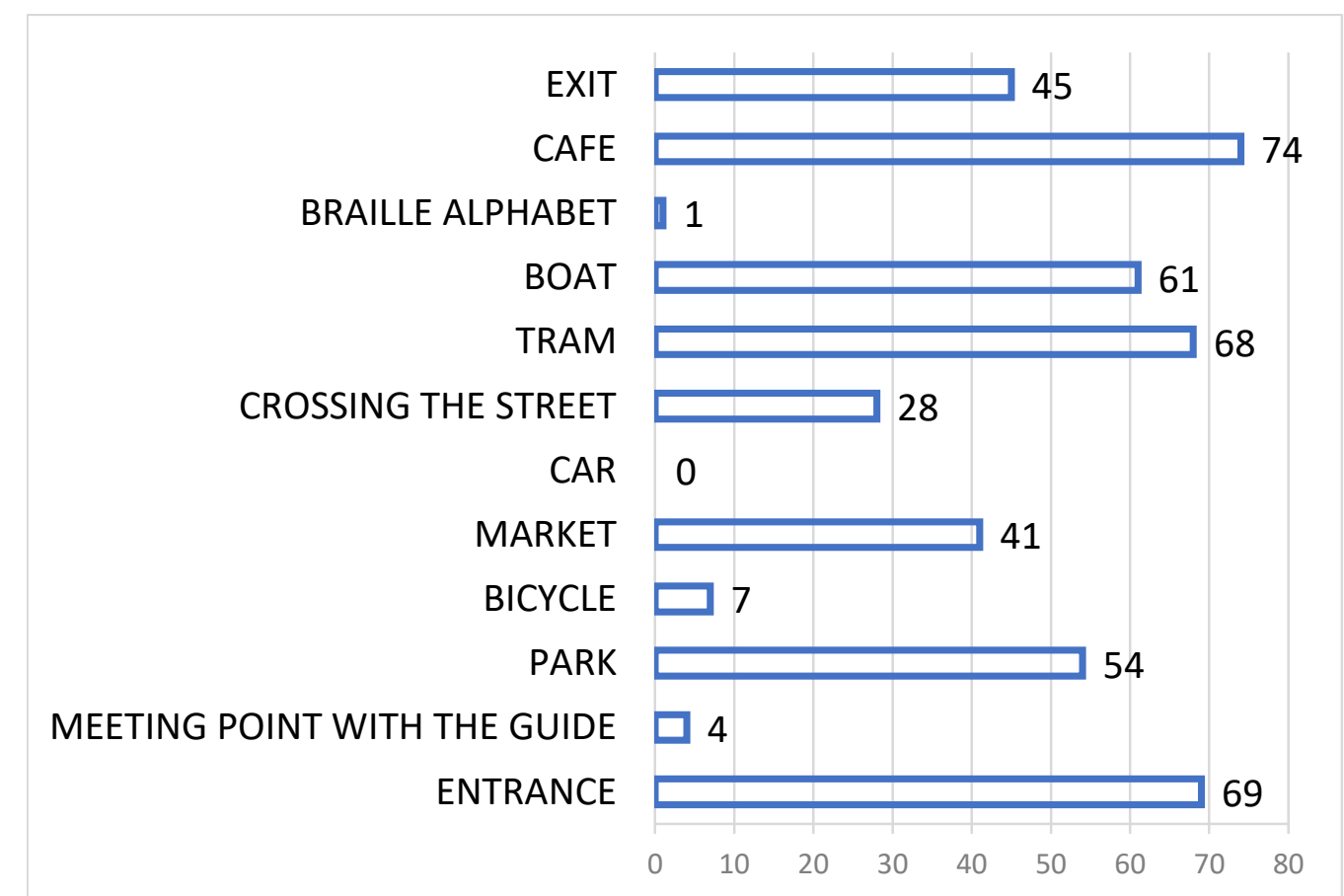

Figure 7. The frequency of each experiential node represented by students on their cognitive maps. 
When the café node is examined through the observation of the notes written by the participants on their cognitive maps, it is encountered with some details that appeal to many olfactory, auditory, tactile and gustative senses; olfactory details such as smell of drinks and perfume, auditory details such as music, sound of people and kettle sound, tactile details such as wooden countertop, money/coins and warmth of drinks, gustative details such as tea, mineral water, chocolate and coke. Moreover, since this experiential node is the place where the blind guides share their memories with the group that cause them to be blind and the difficulties they experience in their daily lives, the participants may be keeping this striking experience in their memories through this experiential node.

The second node which is reflected on the cognitive maps at the highest frequency is the entrance node with 69 (Figure 7). Entrance node is the place where the participants are directed into the setting by a staff, take their walking sticks, and then cross the labyrinthine corridors and switch from light to total darkness alone within the group. This node may have been kept in the memories of the participants as the node where they experienced such a total darkness for the first time and the tension started. Because this is the place where the feeling of security provided by the group of people you are moving with when you are in the light gradually disappears and the feeling of loneliness prevails as you get immersed into the darkness although you keep moving with the same group. Moreover, when the notes written down as sensual details are examined, the labyrinthian walls and height difference detail, which are the tactile sensual details represented, attract particular attention.

Third node represented on the maps at the highest frequency is the tram with 68 as it is stated in the same figure (Figure 7). When the node of tram is examined by observing the notes written by the participants on the cognitive maps, it is noticed that the auditory and tactile details appear strikingly in the cognitive maps; auditory details such as city sounds, music, sound of people and tactile details such as height difference, seats, metal railings and hard flooring apparently kept this node in mind of the participants.

When the cognitive maps of the participants are examined in detail, it is also noticed that the participants not only represented the nodes they visited, but also represented many sensual details that they recognised at these nodes. When the distribution of the frequencies of these sensual data dependent on the sense of smelling, hearing, touching and tasting is correspondingly examined as it is specified in Figure 8; the tactile sensual details are significantly higher in cognitive maps with the amount of 486 compared to other senses of smelling, hearing, and tasting.

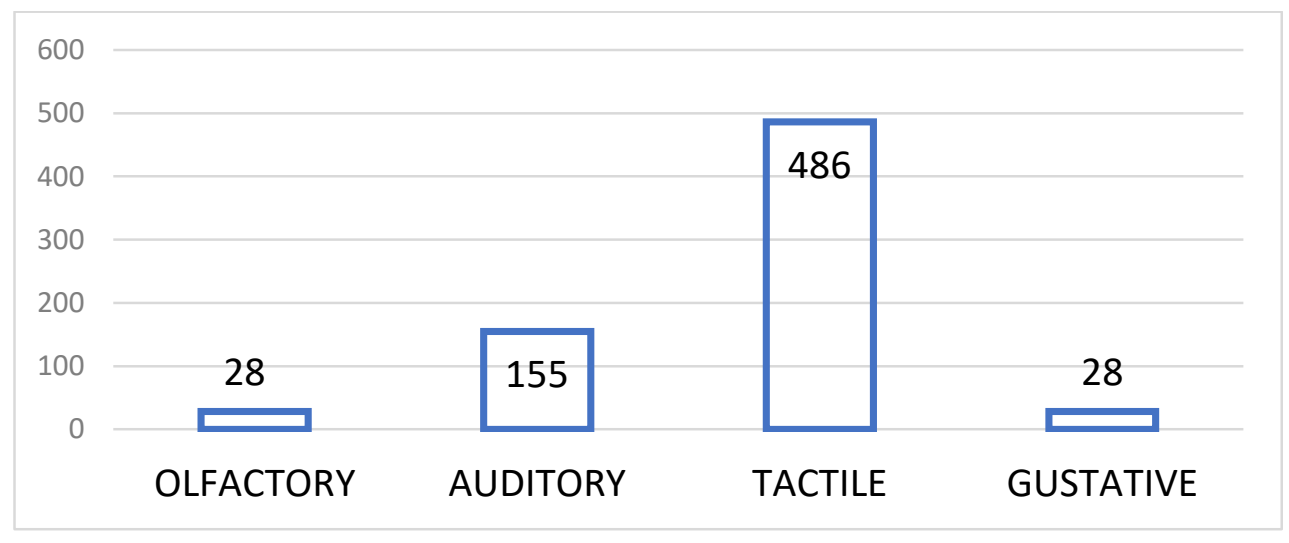

Figure 8. The amount of sensual data on students' cognitive maps. 
The dominant result regarding the tactile data as it is stated above (Figure 8) might be showing the fact that when participants are intertwined

\subsection{Statistical Correlations}

The last step of the research is composed of statistical analyses which are performed using

Table 2. Tests of Normality

\begin{tabular}{|l|l|l|l|l|l|l|}
\hline \multicolumn{4}{|l|}{ Kolmogorov-Smirnov } & \multicolumn{3}{l|}{ Shapiro-Wilk } \\
\cline { 2 - 7 } & Statistic & df & Sig. & Statistic & df & Sig. \\
\hline freqofplace & 191 & 12 & $.200^{*}$ & .882 & 12 & .092 \\
\hline *. This is a lower bound of the true significance. \\
a. Lilliefors Significance Correction \\
\hline
\end{tabular}

with such a complete darkness, they could possibly be recalling the nodes which they have accumulated the greatest amount of tactile data so that they reflect those experiential nodes the most on their cognitive maps. Moreover, when the distribution of the emergence frequency of the sensual data is examined (Figure 9), it is found out that most of the tactile data appeared in the cognitive maps is represented in the first 10 minutes of the cognitive mapping session. This result reflects that the participants might be conveying tactile data primarily while they are representing their experiences in Dialog in the Dark. the SPSS (2018). To choose whether a parametric test or a non-parametric test to be applied, firstly a normality test is performed. When the result of the normality test is analysed (Table 2), the Shapiro-Wilk value is obtained since sample number is less than 50 (the number of experiential nodes: 12<50). Since the Shapiro-Wilk value is 0.092 (> 0.05), the sample size is normally distributed so that a parametric test can be applied. Thus, simple linear regression analyses are conducted in the study since the difference between two dependent variables is sought to be analysed.

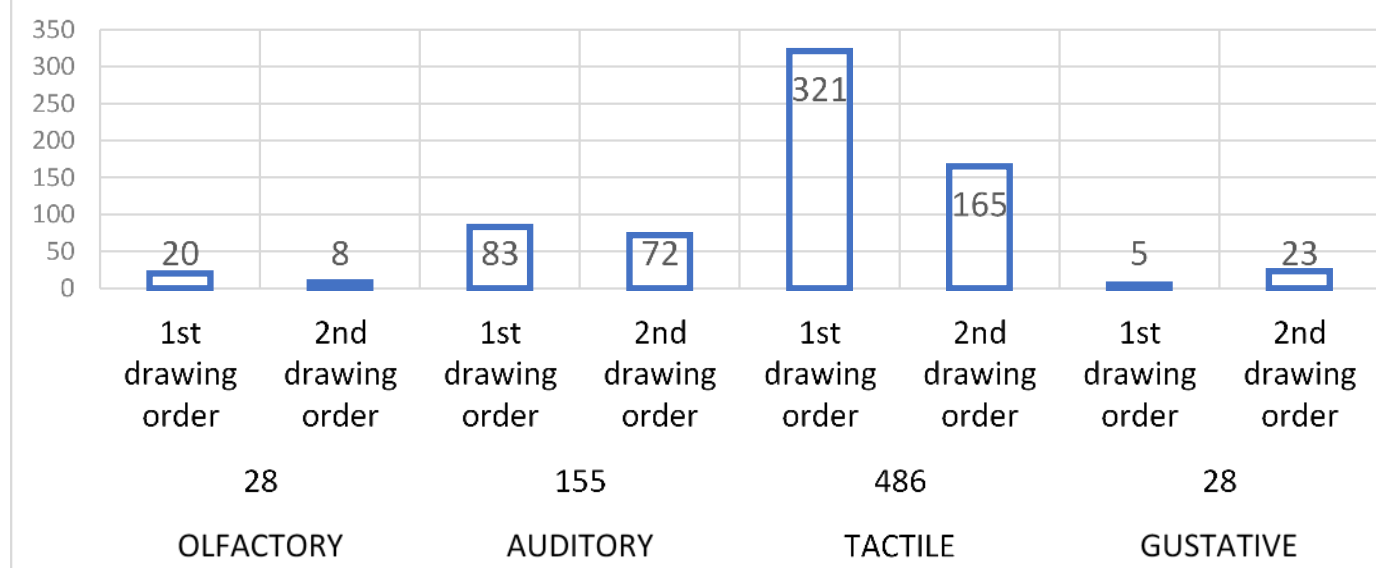

SENSUAL DATA according to drawing order

Figure 9. The frequency of sensory data in the $1^{\text {st }}$ and $2^{\text {nd }}$ cognitive mapping sessions. 
Simple linear regression analyses are conducted between two dependent variables which are, (1) the total frequency of each experiential node represented on cognitive maps, and (2) the total sensual frequency of each experiential node represented on cognitive maps. When the results of all linear regression analyses conducted in the study are examined (Table 3 ), it is seen that 2 out of 12 correlations are significant.

According to the table below (Table 3), no significant relationship is found between the frequency of representation of experiential nodes by the participants and the total frequency of olfactory, auditory and gustative data representations. Additionally, regarding these
But unlike the results of those three sensory datasets, two significant relationships are found (Table 3) between the frequency of representation of experiential nodes by the participants and the total tactile data representations on cognitive maps. There is a significant relationship between the total frequency of the experiential nodes represented in cognitive maps and the tactile characteristics of these nodes $\left(\mathrm{r}^{2}=0.636, \mathrm{p}=0.026<0.05\right)$. In other words, tactile accumulated data of the participants were significantly influential on their recalling behaviours.

When the correlation between the frequency of representation of the nodes and the frequency of

Table 3. Chart showing the simple linear regression correlations between the frequency of the places (experiential nodes) in cognitive maps and the frequency of sensual data.

\begin{tabular}{|l|l|l|l|}
\hline & $\begin{array}{l}\text { Pearson } \\
\text { correlation } \\
\text { value }\left(r^{2}\right)\end{array}$ & $\begin{array}{l}\text { Sig. } \\
\left(\begin{array}{l}\text {-tailed }) \\
p \text { value }\end{array}\right.\end{array}$ & significance \\
\hline Frequency of nodes; total olfactory data & 0.156 & 0.628 & insignificant \\
\hline Frequency of nodes; olfactory data in $1^{\text {st }}$ stage & 0.100 & 0.757 & insignificant \\
\hline Frequency of nodes; olfactory data in $2^{\text {nd }}$ stage & 0.317 & 0.315 & insignificant \\
\hline Frequency of nodes; total auditory data & 0.516 & 0.086 & insignificant \\
\hline Frequency of nodes; auditory data in $1^{\text {st }}$ drawing stage & 0.472 & 0.121 & insignificant \\
\hline Frequency of nodes; auditory data in $2^{\text {nd }}$ drawing stage & 0.540 & 0.070 & insignificant \\
\hline Frequency of nodes; total tactile data & 0.636 & 0.026 & significant \\
\hline Frequency of nodes; tactile data in $1^{\text {st }}$ drawing stage & 0.523 & 0.81 & insignificant \\
\hline Frequency of nodes; tactile data in $2^{\text {nd }}$ drawing stage & 0.660 & 0.020 & significant \\
\hline Frequency of nodes; total gustative data & 0.410 & 0.185 & insignificant \\
\hline Frequency of nodes; gustative data in $1^{\text {st }}$ drawing stage & 0.399 & 0.198 & insignificant \\
\hline Frequency of nodes; gustative data in $2^{\text {nd }}$ drawing stage & 0.142 & 0.183 & insignificant \\
\hline
\end{tabular}

sensory datasets, there are no significant results neither in the first nor in the second drawing stages. Although these results indicate that smell, olfaction and taste data are somewhat effective in remembering, they are not significantly effective in remembering in such a completely dark environment. the tactile dataset according to the drawing stages is examined, it can be mentioned that the frequency of tactile characteristics of the nodes significantly appeared at the $2^{\text {nd }}$ stage of cognitive mapping session $\left(\mathrm{r}^{2}=0.660\right.$, $\mathrm{p}=0.020<0.05)$. When the researcher's own observations regarding the cognitive maps are 
also added, this result might be showing the fact that the participants firstly represented all the nodes they experienced from the beginning to the end within the first ten minutes, and in the second ten minutes which is the second stage of the session, they depicted these nodes with a significantly high amount of tactile data.

When these two significant results are to be evaluated together, it can be discussed that in cases where the sighted individuals are forced to navigate through in a totally dark environment, they tend to rely on their kinaesthetic perceptions through their bodily experiences so that they try to grasp the environment predominantly through its tangible characteristics and trust on their tactile perceptions.

\section{Conclusion and Discussion}

Elective courses are the ones in architecture and design schools through which students explore the physical, social, cultural and psychological aspects of the space with various methodologies and contribute to their development in architectural project studio courses with these aspects. The courses that enable students to discover the invisible dimensions of the space, to help students perceive the space and to realize the interaction between different uses, are the courses that try to reflect the psychosocial characteristics of space. In this context, The Spatial Perception and Cognition course is an elective course that helps the students to grasp that the space is not only composed of topological qualities like $\mathrm{x}, \mathrm{y}$ and $\mathrm{z}$ dimensions and certain square meters but additionally is also composed of psychosocial characteristics that can be comprehended through a holistic perception.

In order to better understand and teach that the space has an invisible psychosocial aspect, this elective course invites its participants to a kinaesthetic experience based on a voluntary participation that the students can explore and navigate in a totally dark environment where the visual perception has become dysfunctional so that they are forced to use their other senses to uncover the psychosocial aspects of space.
When the results obtained at the cognitive mapping session after the students' kinaesthetic experience are considered, it is revealed that when the eyesight -which is the dominant sense in spatial perception- is eliminated, other senses also play a very important role for the individuals in grasping, perceiving, comprehending and recalling any space and accordingly effecting the construction of a cognitive map. Additionally, it is noticed that the tactile sense, compared to the auditory, olfactory and gustative senses, stands out significantly in the perceptual production of space. Additionally, it was revealed via some text notes and graphics that the participants used on their cognitive maps that students are still able to perceive, represent and achieve to uncover the concept of space through many sensory data such as voice, music, wind, material quality of surfaces, temperature, height difference and etc.

In conclusion, it is found out that the elective course Spatial Perception and Cognition, in line with the objectives of the course, have an act as a means to comprehend the psychosocial characteristic of space for the purpose of supporting the students to acquire a more holistic approach in the design process and design thinking and develop their skills helping them to achieve better in their design studio works. Therefore, this study showed that an elective course on spatial perception and cognition within the architecture curriculum in order to examine the concept of space in a multidimensional way thanks to a bodily experience and a subsequently held hands-on experience of a cognitive mapping session, may have an effect in contribution to the students' spatial organization skills in architecture design studios. Additionally, the question of whether students who are considered to have a better understanding of the multifaceted relationship between space and the individual through this course achieve higher success in design studios may also be an important research topic in future studies. 


\section{Acknowledgement}

I thank all the students who have taken Spatial Perception and Cognition course and voluntarily participated in the Dialogue in the Dark event.

\section{References}

Bachelard, G. (1994). The poetics of space Beacon Press. Boston MA.

Barker, R.G. (1968). Ecological Psychology; Concepts and Methods for Studying Human Behavior. California: Stanford University Press.

Canter, D. (1977). The Psychology of Place, London: The Architectural Press Ltd.

Downs, R. M. and Stea, D. (1973). Cognitive maps and spatial behavior: Process and products. In M. Dodge, R. Kitchin, and C. Perkins (Eds.), The Map Reader: Theories of Mapping Practice and Cartographic Representation, (p.312-317). London: John Wiley \& Sons.

Gibson, J. J. (1966). The Senses Considered as Perceptual Systems, Boston: Houghton Mifflin.

Gibson, J. J., (1979). The Ecological Approach to Visual Perception, Boston: Houghton Mifflin.

Hall, E. (1966). The Hidden Dimension, New York, US: Doubleday \& Company, Inc. Garden City.

Hart, R. A., \& Moore, G. T. (1973). The development of spatial cognition: A review. In R.M. Downs, D. Stea (Eds.), Image \& environment: Cognitive mapping and spatial behavior, (pp. 246-288). New Brunswick, NJ, US: Aldine Transaction.

Ittelson, W. H. (1951). The constancies in perceptual theory. Psychological Review, 58(4), 285.
Ittelson, W., Rivlin, L., Proshansky, H. M. (1976). The use of Behavioural Maps in Environmental Psychology. New York, NY: Holt, Rinehart and Winston.

Jacobson, J. L., (1998). Cognitive Mapping Without Sight: Four Preliminary Studies of Spatial Learning, Journal of Environmental Psychology, 18, 289-305.

Kaplan, S. (1973). Cognitive maps in perception and thought. Image and environment: Cognitive mapping and spatial behavior, 63-78.

Lawson, B. (2001). Language of Space, Oxford: Architectural Press.

Lawton, M. \& Nahemow, L. (1973). Ecology and the aging process. In C. Eisdorfer and M. Lawton (Eds.), The psychology of adult development and aging. (pp. 619-674). Washington: American Psychological Association.

Lynch, K. (1960). The Image of the City, Cambridge: MIT Press.

Merleau-Ponty, M. (1961). Eye and mind, Images: A Reader.

Merleau-Ponty, M. (1982). Phenomenology of perception, London: Routledge.

Merleau-Ponty, M. (2004). The world of perception, London: Routledge.

Moore, G. T. (1979). Architecture and human behavior: The place of environment-behavior studies in architecture. Wisconsin Architect, $18-21$.

Moore, G. T. (1985). Environment and behavior research in North America: History, developments, and unresolved issues. Center for Architecture and Urban Planning Research, University of Wisconsin-Milwaukee. 
Pallasmaa, J. (2005). The eyes of the skin: Architecture and the senses. NJ, USA: John Wiley \& Sons.

Passini, R., \& Proulx, G. (1988). Wayfinding without vision: An experiment with congenitally totally blind people. Environment and behavior, 20(2), 227-252.

Piaget, J., Inhelder, B. (1967). The Child's Conception of Space. New York, USA: The Norton Library.

Rapoport, A. (1969). House form and culture. Engelwood Cliffs, NJ: Printice-Hall.

Rock, I., Palmer, S. (1990). The legacy of Gestalt psychology. Scientific American, 263(6), 84-91.

Sarıberberoğlu, M. T., Turgay, Z. T., Canakcioglu, N. G. (2017). Cognition through a nonvisual experience, Iconarch III International Congress of Architecture Memory of Place in Architecture and Planning Congress, May 1113, 2017, Konya, Turkey.

Smith, B. (1988). Foundations of Gestalt theory, Philosophia Resources Library, Münich: Philosophia Verlag Gmbh,
Sommer, R. (1959). Studies in personal space. Sociometry, 22(3), 247-260.

SPSS (Statistical Package for Social Sciences) software, IBM [Computer Software], (2018). Retrieved from https://www.ibm.com/trtr/products/spss-statistics

Tolman, E. C. (1948). Cognitive maps in rats and men. Psychological review, 55(4), 189.

Ungar, S. 2000. Cognitive mapping without visual experience. In Kitchin, R. \& Freundschuh, S. (Eds.), Cognitive Mapping: Past Present and Future. London: Routledge.

Url-1 https://www.dialogue-in-thedark.com/about/exhibition/

Url-2

http://turkcelldiyalogmuzesi.com/karanliktadiyalog

Ünlü, A. (1998). Çevresel Tasarımda İlk Kavramlar (First Concepts in Environmental Design). Istanbul, Turkey: ITU Architecture Faculty Press. 